\title{
Silicone oils compared and found wanting
}

\author{
David H. W. Steel ${ }^{1,2}$ (D) David Wong ${ }^{3} \cdot$ Taiji Sakamoto $^{4}$
}

Received: 11 June 2020 / Revised: 11 June 2020 / Accepted: 17 June 2020 / Published online: 22 June 2020

(C) Springer-Verlag GmbH Germany, part of Springer Nature 2020

Silicone oil was first introduced in the treatment of retinal detachment (RD) by Cibis in the 1960s and approved by the US Food and Drug Administration for intraocular use in 1994 [1]. It was approved as a medical device and its application continues to be under medical device regulations rather than as a medicine. Its use has been associated with a wide variety of complications, and in many cases, these have been thought to be toxic in origin, due to chemical impurities rather than mechanically induced [2]. Indeed, the commonest complication of oil use, emulsification is known to be significantly increased in the presence of low molecular weight polymer impurities in oil [3]. Silicone oil is typically not used as a surgical tool and occasionally left in the eye for prolonged periods including permanently. If newly invented, there is no doubt that there would have been a greater burden of proof needed for its chemical composition and impurity content. In actual fact, if it were not for the fact that oil is indispensable in some cases, its use may have been abandoned some time ago.

There are of course technical reasons purity is difficult to achieve. Silicone oil as used in ophthalmology is a high molecular weight polymer, polydimethylsiloxane (PDMS), written as a formula of repeated units, $\mathrm{CH}_{3}\left[\mathrm{Si}_{(}\left(\mathrm{CH}_{3}\right)_{2} \mathrm{O}\right] \mathbf{n}$ $\mathrm{Si}\left(\mathrm{CH}_{3}\right)_{3}$. Its manufacture involves a multi-step synthesis starting with mainly oligomers (low molecular weight polymers comprising a small number of repeat units of PDMS). The end product is effectively a mixture of polymers (with some cyclic forms) of different molecular weights which are then purified to theoretically leave the desired linear product

David H. W. Steel

David.steel@ncl.ac.uk

1 Sunderland Eye Infirmary, Queen Alexandra Road, Sunderland, UK

2 Bioscience Institute, Newcastle University, Newcastle Upon Tyne, UK

3 St. Paul's Eye Unit, Royal Liverpool University Hospital Trust, Liverpool, UK

4 Department of Ophthalmology, Kagoshima University Graduate School of Medical and Dental Sciences, Kagoshima, Japan polymer only [4]. The viscosity of oil arises from the length of the polymers. Longer chain length with higher molecular weight results in more viscous oil. Silicone oils available have a viscosity ranging from 1000 to $5000 \mathrm{cSt}$, representing molecular weights of approximately 37 to $65 \mathrm{kDa}$. Theoretically, longer chain polymers are harder to purify as they 'trap' LMW chain polymers in their substance [5]. It should also be noted that some newly introduced oils have a mix of very high molecular weight polymers $(423 \mathrm{kDa})$ with conventional length polymers to increase shear viscosity and making passage through narrow gauge cannulas easier, whilst maintaining emulsification resistance by increasing extensional viscosity. Similarly, some 'heavy' oils are mixtures of conventional oils with heavier than water substances such as the semifluorinated alkane, perfluorohexyloctane $[6,7]$.

In this issue, Dresp has shown that the ophthalmic silicone oils available to us vary hugely by manufacturer [8]. Dresp measured polydispersity (as a measure of the range of different polymer chain lengths in the product), a range of oligosiloxanes (short-chain impurities, typically less than $10 \mathrm{kDa}$, and mostly less than $1 \mathrm{kDa}$ which increase emulsification and can also potentially diffuse into the surrounding tissues accumulating and creating inflammatory reactions), and the presence of ultraviolet wavelength (UV) active substances (as a general measure of purity and leachables from packaging, e.g. stoppers on bottles or syringe plungers, and which can affect emulsification). He found that the analysed silicone oils varied significantly for all 3 parameters, not only among different brands but also among batches of the same manufacturer and differing viscosities. Mendichi et al. last year in a study of 10 different manufacturers of lower viscosity oils had similar findings [9]. They also showed that measured viscosities sometimes differed significantly from labelling.

This is a significant problem as not only do we expose our patients to risk but also we are not able to compare like with like. For years, surgeons have had ingrained beliefs about which viscosity oils have the lowest emulsification rates but no one has been able to provide good evidence that one viscosity is truly better than another. Aside from concerns over toxicity testing of agents designed for intraocular use and the 
potential for contamination with combined use of agents, many surgical and patient factors are also known to affect emulsification rates $[10,11]$. These include age, inflammation, cavity fill, use of laser/endodiathermy, and instrument reuse, and this has muddied the waters, but underlying all this, we have been using oils of hugely varying properties, severely hindering our ability to interpret our findings. It is literally intolerable that we do not know the purity of the various products on the market. Without the guidance from published clinical evidence, surgeons make clinical decisions based on their personal experience, convinced by good and bad outcomes from their last series of cases, never knowing whether it was the silicone oil or clinical features or indeed surgical techniques that made the most difference.

In this editorial, on behalf of all vitreoretinal surgeons, we urge all manufacturers to publish a minimum specification dataset to define the purity of their products. These should include measures of polydispersity from the components of their desired product profile, the presence and quantity of low molecular weight residues, and the stability of their product with time for both oligomers and UV-active substances from packaging. The study by Drespe clearly shows that some manufacturers can achieve much better purities than others. We would suggest the following minimum standards be set: for the short-chained siloxanes (L2-L4 and D3-D5), a level of $<$ 1 part per million, $<0.3$ arbitrary units of UV active substances, and a polydispersity index of $<1.7$ for each intended oil component. We have based these on an achievable level as evidenced by having already been reached by some manufacturers.

For the sake of our patients, if surgeons have a choice, we should naturally choose the highest purity and most stable products. The subject we write about is not new. Indeed, oil impurities have been known for some time [12]. We cannot ignore this issue any longer. National and international retinal societies should write open letters to manufacturers asking them to agree, publish, and adhere to high standards of purity. Manufacturers should be left in no doubt that we are asking for consistency, without which our clinical science cannot be taken forward.

\section{References}

1. https://www.accessdata.fda.gov/SCRIPTS/cdrh/devicesatfda/ index.cfm?db=pma\&id=331810. Accessed 7/6/20

2. Barca F, Caporossi T, Rizzo S (2014) Silicone oil: different physical proprieties and clinical applications. Biomed Res Int 2014: 502143

3. Nakamura K, Refojo MF, Crabtree DV, Pastor J, Leong FL (1991) Ocular toxicity of low-molecular-weight components of silicone and fluorosilicone oils. Invest Ophthalmol Vis Sci 32:3007-3020

4. Schatz MF, Howden K (1995) Purification of silicone oils for fluid experiments. Exp Fluids 19:359-361

5. Mojsiewicz-Pienkowska K, Jamrogewicz M, Szymkowska K, Krenczkowska D (2016) Direct human contact with siloxanes (silicones) - safety or risk part 1. Characteristics of siloxanes (silicones). Front Pharmacol 7:132

6. Williams RL, Day M, Garvey MJ et al (2010) Increasing the extensional viscosity of silicone oil reduces the tendency for emulsification. Retina 30:300-304

7. Caramoy A, Kearns VR, Chan YK et al (2015) Development of emulsification resistant heavier-than-water tamponades using high molecular weight silicone oil polymers. J Biomater Appl 30:212220

8. Dresp J. (2020) Benchmarking different brands of silicone oils. Graefes Arch Clin Exp Ophthalmol In Press

9. Mendichi R, Schieroni AG, Piovani D, Allegrini D, Ferrara M, Romano MR (2019) Comparative study of chemical composition, molecular and rheological properties of silicone oil medical devices. Transl Vis Sci Technol 8:9

10. Veckeneer MA, de Voogd S, Lindstedt EW, Menz DH, van Meurs JC (2008) An epidemic of sticky silicone oil at the Rotterdam Eye Hospital. Patient review and chemical analyses. Graefes Arch Clin Exp Ophthalmol 246:917-922

11. Januschowski K, Irigoyen C, Pastor JC et al (2018) Retinal toxicity of medical devices used during vitreoretinal surgery: a critical overview. Ophthalmologica. 240:236-243

12. Gabel VP, Kampik A, Burkhardt J (1987) Analysis of intraocularly applied silicone oils of various origins. Graefes Arch Clin Exp Ophthalmol 225:160-162

Publisher's note Springer Nature remains neutral with regard to jurisdictional claims in published maps and institutional affiliations. 